\title{
Giesela Rühl
}

\section{Statut und Effizienz}

\section{Ökonomische Grundlagen des Internationalen Privatrechts}

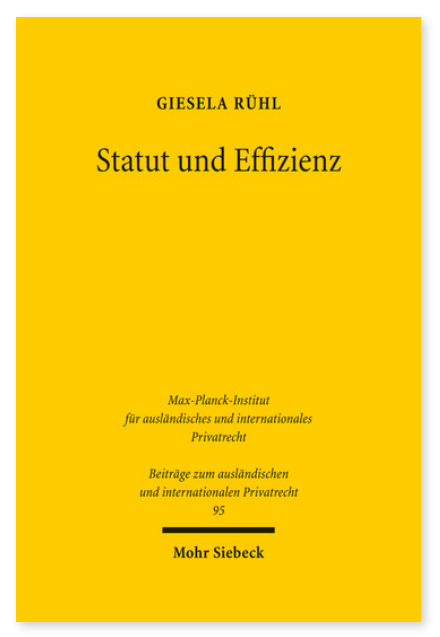

2011. XXXII, 811 Seiten. BtrIPR 95

ISBN 978-3-16-151748-8

DOI 10.1628/978-3-16-151748-8

eBook PDF 129,00€

ISBN 978-3-16-150698-7

Leinen $129,00 €$
Ist das Internationale Privatrecht eine effiziente Antwort auf die Probleme grenzüberschreitender Transaktionen? In ihrer Untersuchung zu den ökonomischen Grundlagen des Internationalen Privatrechts geht Giesela Rühl dieser Frage nach. Sie unterzieht die einschlägigen Normen auf breiter rechtsvergleichender Grundlage einer Analyse mit Hilfe des ökonomischen Instrumentariums und macht Erkenntnisse der ökonomischen Theorie für die Beantwortung konzeptioneller Fragen sowie für die Lösung konkreter Probleme aus dem Internationalen Vertrags- und Deliktsrecht fruchtbar. Indem sie das im Werden begriffene europäische Kollisionsrecht in den Mittelpunkt ihrer Untersuchung rückt, leistet die Autorin gleichzeitig einen Beitrag zur Entwicklung eines kohärenten und funktionsfähigen europäischen Kollisionsrechts sowie zur Herausbildung einer eigenständigen europäischen Kollisionsrechtswissenschaft.

Giesela Rühl ist Inhaberin des Lehrstuhls für Bürgerliches Recht, Zivilverfahrensrecht, Europäisches und Internationales Privat- und Verfahrensrecht und Rechtsvergleichung an der Humboldt-Universität zu Berlin.
Jetzt bestellen:

https://mohrsiebeck.com/buch/statut-und-effizienz-9783161517488?no_cache=1

order@mohrsiebeck.com

Telefon: +49 (0)7071-923-17

Telefax: $+49(0) 7071-51104$ 